\title{
ESTUDO DA TURBULÊNCIA ATMOSFÉRICA NOTURNA SOBRE COXILHAS (ESTÂNCIA). PARTE 2: RESULTADOS PRELIMINARES
}

\author{
Otávio C. Acevedo ${ }^{1}$ Pablo E. S. Oliveira ${ }^{1}$, Daniel M. Santos ${ }^{1}$, Guilherme M. Silva, \\ Luiz Eduardo Medeiros ${ }^{1}$, Mario F. L. Quadro ${ }^{2}$, Márcia V. Fuentes ${ }^{2}$, Marcelo S. Bastos², \\ Anderson S. Nedel ${ }^{3}$

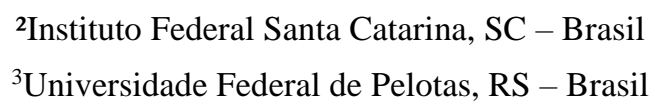

\section{RESUMO}

Uma campanha micrometeorológica foi conduzida nos meses de agosto e setembro de 2013 com o objetivo de identificar padrões de variabilidade espacial de variáveis meteorológicas em noites de pouco vento, em escalas horizontais de centenas de metros. Neste trabalho, alguns resultados preliminares são apresentados.

\section{INTRODUÇÃO}

De 27 de agosto a 23 de sembro de 2003, o Laboratório de Micrometeorologia da UFSM conduziu em cooperação com o grupo de Meteorologia do Instituto Federal Santa Catarina (IFSC) uma campanha de observações em que 11 estações meteorológicas foram instaladas em uma área de cerca de 90 hectares. O objetivo principal é caracterizar a variabilidade espacial de grandezas meteorológicas em noites de pouco vento e compará-las com o que é observado em noites de grande mistura turbulenta. Na primeira parte deste trabalho, foi feita uma descrição mais detalhada da região e das medidas realizadas. Nesta parte, se apresentará uma descrição geral de alguns resultados preliminares.

\section{RESULTADOS PRELIMINARES}

Padrões diferentes de variabilidade horizontal ocorreram nas noites distintas, dependendo na mistura turbulenta em cada uma delas (figura 1). Nas noites mais estáveis, como a de 30 para 31 de agosto, os gradientes horizontais de temperatura atingiram valores 
extremamente altos, chegando a mais de $10^{\circ} \mathrm{C}$ de diferença de temperatura entre estações afastadas horizontalmente por apenas $300 \mathrm{~m}$. As estações mais quentes foram as mais altas, que se mantiveram turbulentas ao longo da noite, enquanto as mais baixas, nas quais houve desacoplamento entre a superfície e os níveis mais altos da atmosfera, com consequente acúmulo de ar frio, experimentaram acentuada queda de temperatura. A diferença de altura entre as estações mais altas e as mais baixas é de cerca de $25 \mathrm{~m}$. Trabalhos anteriores (Acevedo e Fitzjarrald 2001, LeMone et al., 2003) já haviam registrado diferenças de temperatura semelhantes, mas não em uma escala horizontal tão pequena.

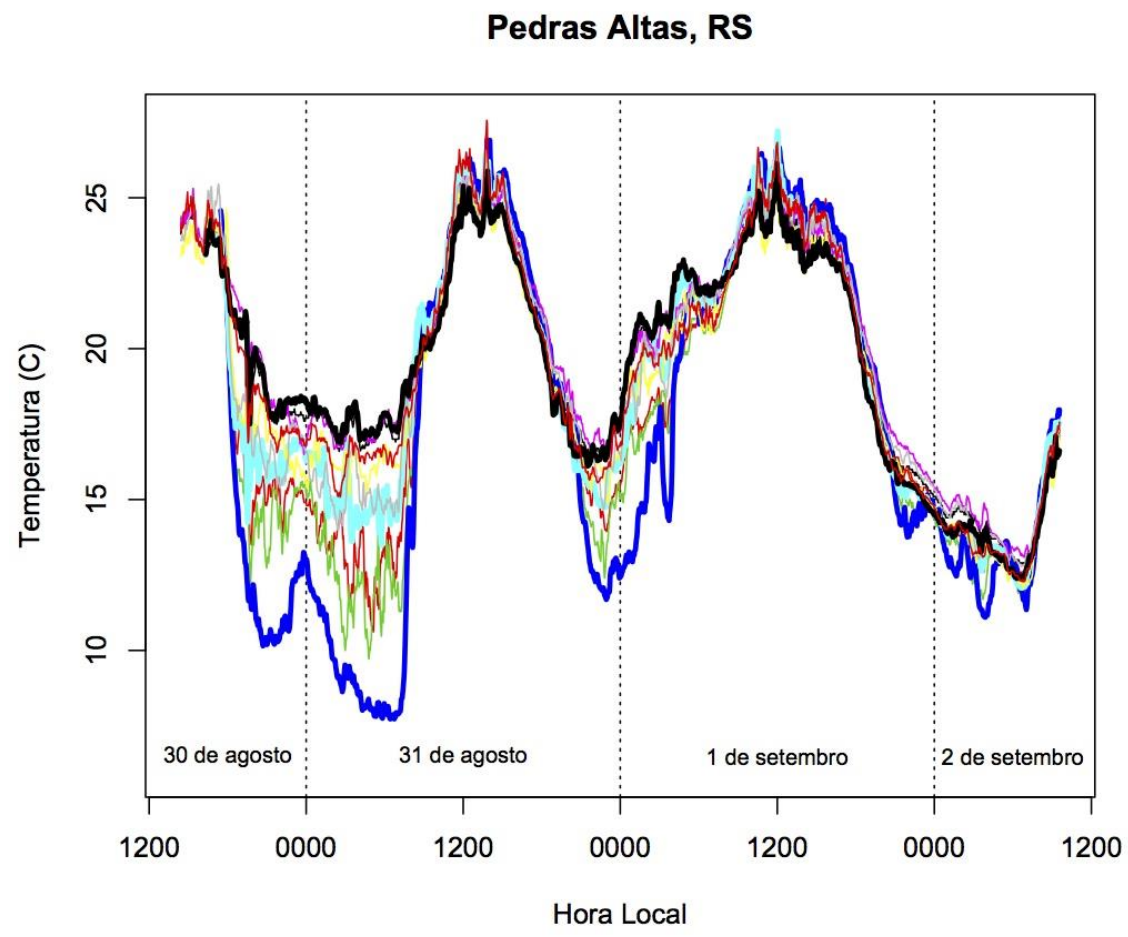

Figura 1. Evolução temporal da temperatura do ar nas 11 estações. As linhas mais espessas indicam estações onde medidas de turbulência estavam disponíveis, sendo a azul situada em um vale, a preta no alto de um morro.

A noite de 31 de agosto para 1 de setembro, por sua vez, apresentou dois padrões distintos. Na primeira metade da noite, começou a se estabelecer uma diferença grande de temperatura entre as estações, que atingiu $7^{\circ} \mathrm{C}$ entre as estações mais extremas logo após a meia-noite. Porém, na segunda metade da noite a variabilidade diminui, havendo apenas eventos esporádicos de esfriamento na estação mais baixa. A terceira noite apresentada na 
figura 1 é a que tem características mais homogêneas, apenas com eventos intermitentes de diferença significante de temperatura ocorrendo na estação mais baixa (linha azul espessa)
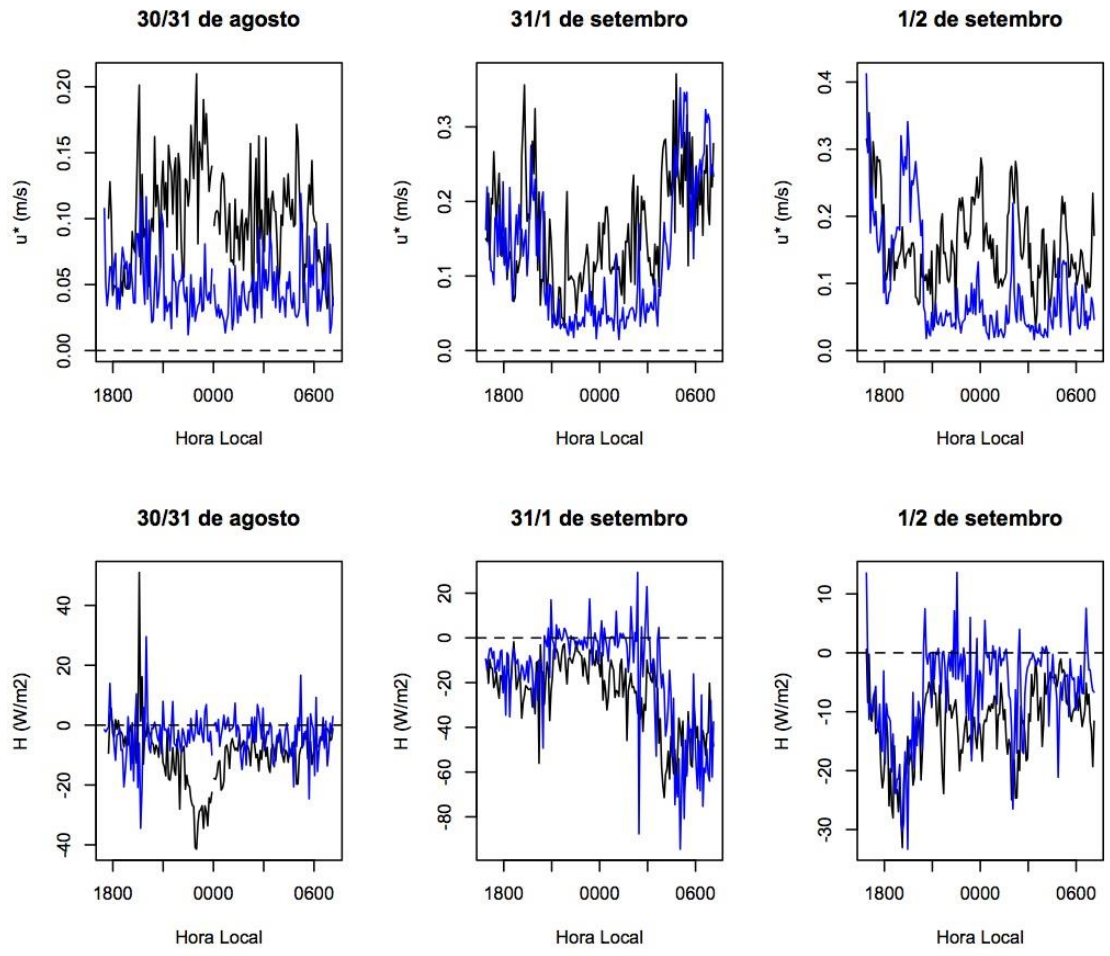

Figura 2. Painéis superiores mostram velocidade de fricção nas três noites apresentadas na figura 1 para a estação de fluxo alta (linha preta) e baixa (azul). Nos painéis inferiores é o mesmo, mas para fluxos de calor sensível.

Observações de velocidade de fricção e fluxos turbulentos nas estações mais alta e mais baixa confirmam a relação entre a variabilidade observada de temperatura e a mistura turbulenta. Na noite de 30 para 31 de agosto, apenas a estação mais alta se mantém turbulenta durante a noite, com a localidade mais baixa permanecendo o período todo com mistura turbulenta e fluxos bastante reduzidos. Nesta noite, é interessante observar o evento que ocorreu em torno da meia noite, com grandes fluxos na localidade mais alta. Neste evento, a temperatura da região mais alta pouco variou, pois esta já se encontrava conectada a níveis mais altos pela mistura turbulenta. Porém, no mesmo momento um aumento de cerca de $3^{\circ} \mathrm{C}$ de temperatura se verificou na localidade mais baixa, $300 \mathrm{~m}$ distante. Por sua vez, a noite de 31 de agosto para 1 de setembro se mostrou pouco turbulenta até a meianoite, com subsequente aumento da mistura, que explica os diferentes padrões de 
temperatura em cada período. Já em 1 para 2 de setembro, houve turbulência intermitente na localidade mais baixa, responsável pelas bruscas variações de temperatura observadas naquele local e apenas ali.

\section{CONCLUSÃO}

Os resultados preliminares indicam que as observações capturaram a diferença entre noites com e sem variabilidade espacial das grandezas atmosféricas e que estas estão associadas à mistura turbulenta. A análise mais detalhada permitirá identificar como se estabelecem os padrões de variabilidade espacial e qual suas implicações

\section{REFERÊNCIAS}

ACEVEDO, O. C., D. R. FITZJARRALD, The early evening surface layer transition: temporal and spatial variability. J. Atmos. Sci, 58, 2650-2667, 2001.

LE MONE, M. A., K. IKEDA, R. L. GROSSMAN, M. W. ROTACH, Horizontal variability of 2-m temperature at night during CASES-97 J. Atmos. Sci, 60, 2431-2449, 2003. 